\title{
Prevalence, distribution, and social determinants of tobacco use in 30 sub-Saharan African countries
}

\author{
Chandrashekhar T Sreeramareddy ${ }^{1 *}$, Pranil Mansingh Pradhan ${ }^{2}$ and Shwe $\operatorname{Sin}^{3}$
}

\begin{abstract}
Background: Although the Framework Convention on Tobacco Control prioritizes monitoring of tobacco use by population-based surveys, information about the prevalence and patterns of tobacco use in sub-Saharan Africa is limited. We provide country-level prevalence estimates for smoking and smokeless tobacco (SLT) use and assess their social determinants.
\end{abstract}

Methods: We analyzed population-based data of the most recent Demographic Health Surveys performed between 2006 and 2013 involving men and women in 30 sub-Saharan African countries. Weighted country-level prevalence rates were estimated for 'current smoking' (cigarettes, pipe, cigars, etc.) and 'current SLT use' (chewing, snuff, etc.). From the pooled datasets for men and women, social determinants of smoking and SLT use were assessed through multivariate analyses using a dummy country variable as a control and by including a within-country sample weight for each country.

Results: Among men, smoking prevalence rates were high in Sierra Leone (37.7\%), Lesotho (34.1\%), and Madagascar (28.5\%); low (<10\%) in Ethiopia, Benin, Ghana, Nigeria, and Sao Tome \& Principe; the prevalence of SLT use was $<10 \%$ in all countries except for Madagascar (24.7\%) and Mozambique (10.9\%). Among women, smoking and SLT prevalence rates were $<5 \%$ in most countries except for Burundi (9.9\%), Sierra Leone (6\%), and Namibia (5.9\%) (smoking), and Madagascar (19.6\%) and Lesotho (9.1\%) (SLT use). The proportion of females who smoked was lower than SLT users in most countries. Older age was strongly associated with both smoking and SLT use among men and women. Smoking among both men and women was weakly associated, but SLT use was strongly associated, with education. Similarly, smoking among men and women was weakly associated, but SLT use was strongly associated, with the wealth index. Smoking and SLT use were also associated with marital status among both men and women, as well as with occupation (agriculturists and unskilled workers).

Conclusions: Prevalence of smoking among women was much lower than in men, although the social patterns of tobacco use were similar to those in men. Tobacco control strategies should target the poor, not/least educated, and agricultural and unskilled workers, who are the most vulnerable social groups in sub-Saharan Africa.

\section{Background}

Tobacco use has been long known to be a major cause of premature mortality [1] and has been attributed to cause $9 \%$ of all deaths worldwide [2]. Each year, an estimated 5.7 million deaths, $6.9 \%$ of years of life lost, and $5.5 \%$ of disability adjusted life years are caused by tobacco-related diseases [3]. The prevailing pattern of the tobacco epidemic could cause one billion deaths

\footnotetext{
* Correspondence: chandrashekharats@yahoo.com

'Department of Population Medicine, Faculty of Medicine and Health Sciences, Universiti Tunku Abdul Rahman, Bandar Sungai Long, Selangor 43000, Malaysia

Full list of author information is available at the end of the article
}

during the $21^{\text {st }}$ century and $80 \%$ of them could occur in low- and middle-income countries (LMICs) [4]. Though recent global estimates have shown a decreasing trend of smoking among both men and women, in 2012 there remained an estimated 967 million smokers living in 187 countries, with the number being expected to increase as the population grows [5].

The Framework Convention on Tobacco Control (FCTC) adopted in 2003 has been ratified by 177 countries worldwide [6]. Under the FCTC, monitoring of tobacco use worldwide by population-based surveys has been prioritized to understand disease patterns, assess the impact of tobacco control measures, and to assist tobacco control policy 
changes [7]. Major steps in this direction are the Global Tobacco Surveillance system [8], World Health Organization's STEPS program [9], World Health Surveys (WHS) [10], and the International Tobacco Control (ITC) policy evaluation project [11] carried out in a number of countries spanning all continents. Nevertheless, data from these surveys do not comprehensively reflect tobacco use estimates, patterns, and types of tobacco products consumed in sub-Saharan Africa (SSA). For example, smokeless tobacco (SLT) products commonly consumed in South and South-East Asia [12] have health effects that are different from those of smoking $[13,14]$ and are usually not emphasized much in tobacco control policies. This assumes great importance since the type of tobacco products consumed not only varies across countries [15] and regions [5], but also by age, gender, education, and economic status [16-19].

Among the multi-country surveys, tobacco use data from 14 SSA countries is available from the WHS [10] and Nigeria and Uganda in GATS [20], but none from ITC projects [11]. Further, the WHS and ITC projects focus on cigarette smoking only $[11,17]$. Information about tobacco use gathered from Demographic and Health Surveys (DHSs) performed on nationally representative samples of men and women can provide national-level estimates for each country and study the social distribution of tobacco use and type of tobacco products consumed in a particular region [15]. Pampel has provided estimates of cigarette smoking and its social determinants from DHSs performed in 14 SSA countries during the year 2006 or prior [21]. However, Pampel's study does not provide estimates of SLT use and distribution of tobacco use by economic (wealth) status [21]. A systematic review of studies on adult tobacco use prior to the year 2005 in 14 SSA countries showed that the information varied due to the heterogeneity of the included studies [22]. The scale and pattern of the tobacco epidemic currently prevailing in the SSA countries is not clearly known except for some reports based on DHSs from Ghana [23] and Madagascar [24] and a national survey from Mozambique [25]. Inclusion of tobacco use questions in 30 countries' DHSs during recent years provides a clear picture of the tobacco epidemic in the SSA region [26]. We aim to provide country-level prevalence estimates for smoking and SLT use and assess their social distribution (determinants) in 30 SSA countries.

\section{Methods}

\section{Data source}

We performed retrospective, secondary data analyses of the most recent DHSs, which are nationally representative, cross-sectional, household surveys. DHSs aim to provide reliable data on fertility, family planning, health and nutrition, health services utilization, health knowledge, and behaviors in more than 85 LMICs. DHSs are conducted by in-country/local institutions with funding from the United States Agency for International Development and technical assistance from the Opinion Research Corporation (ORC) Macro International Inc., Calverton, Maryland, USA [27]. The original microdata sets of the DHSs which had collected data about tobacco use in 30 SSA countries between 2006 and 2013 were downloaded from the DHS program [28] with their written permission. DHSs select households by two-stage stratified cluster sampling designs and usually oversampling is performed in the less populated provinces. In general, the DHS sampling method identifies clusters from both urban and rural areas by the probability proportional to size technique followed by a random selection of households from within the selected clusters. The head of each selected household answers all general questions about the household and lists the household members who reside there. Trained interviewers collect the data from all eligible men and women aged $15-49$ years (in many countries men aged up to 64 years were interviewed) according to standard protocols using pretested questionnaires in local languages and their supervisors ensure that guidelines are adhered to for quality control and minimizing nonresponse $[26,27]$. The survey characteristics of DHSs from 30 countries included for our analyses are provided in Table 1.

\section{Outcome variable}

We constructed a nominal outcome variable as 'current smoking' (cigarettes, pipe, cigars, etc.) and 'current SLT use' (chewing, snuff, etc.) based on responses provided to four main questions about tobacco use asked in both men's and women's questionnaires. The questions adopted were fairly similar in structure except for the response options in some countries. The respondents were asked four questions for which 'yes' or 'no' responses were available for the first two. A general outline of the questions is as follows:

1) Do you currently smoke cigarettes? Yes/No

2) Do you currently smoke or use any other type of tobacco? Yes/No

3) What (other) type of tobacco do you currently smoke or use? (pipe, chewing tobacco, snuff, etc.)

4) Over the past 24 hours, how many cigarettes have you smoked? (response as a numerical)

\section{Social variables}

To study the social distribution of tobacco use, we used age (in single years), religion (classified as Islam, Catholic, Protestant, other Christian, and other/no religion), marital status (classified as 'not in union', 'married', 'living together', and 'single' which includes separated, widowed, and divorced), place of residence (classified as 'rural' 
Table 1 Survey characteristics, sample sizes, and response rates for men and women participants of Demographic and Health Surveys in $\mathbf{3 0}$ countries in sub-Saharan Africa

\begin{tabular}{|c|c|c|c|c|c|}
\hline Country & Dates field work & Households & Women & Men & Overall response rate (\%) \\
\hline \multicolumn{6}{|l|}{ EASTERN AFRICA } \\
\hline 1. Burundi & August 2010 - January 2011 & 8,596 & 9,389 & 4,280 & 95.5 \\
\hline 2. Comoros & August 2012 - December 2012 & 4,482 & 5,329 & 2,167 & 94.7 \\
\hline 3. Ethiopia & December 2010 - May 2011 & 16,702 & 16,515 & 14,110 & 93.2 \\
\hline 4. Kenya & November 2008 - February 2009 & 9,057 & 8,444 & 3,465 & 94.1 \\
\hline 5. Madagascar & November 2008 - August 2009 & 17,857 & 17,375 & 8,586 & 94.4 \\
\hline 6. Malawi & June 2010 - November 2010 & 24,825 & 23,020 & 7,175 & 95.1 \\
\hline 7. Mozambique & June 2011 - November 2011 & 13,919 & 13,745 & 4,035 & 98.9 \\
\hline 8. Rwanda & September 2010 - March 2011 & 12,540 & 13,671 & 6,329 & 98.9 \\
\hline 9. Tanzania & December 2009 - May 2010 & 9,623 & 10,139 & 2,527 & 95.2 \\
\hline 10. Uganda & June 2011 - December 2011 & 9,033 & 8,674 & 2,295 & 89.4 \\
\hline 11. Zambia & April 2007 - October 2007 & 7,164 & 7,146 & 6,500 & 94.3 \\
\hline 12. Zimbabwe & September 2010 - March 2011 & 9,756 & 9,171 & 7,480 & 89.5 \\
\hline \multicolumn{6}{|l|}{ WESTERN AFRICA } \\
\hline 13. Benin & December 2011 - March 2012 & 17,422 & 16,599 & 5,180 & 94.4 \\
\hline 14. Burkina Faso & May 2010 - January 2011 & 14,424 & 17,087 & 7,307 & 97.7 \\
\hline 15. Cote d'Ivoire & December 2011 - May 2012 & 9,686 & 10,060 & 5,135 & 91.0 \\
\hline 16. Ghana & September 2008 - November 2008 & 11,778 & 4,916 & 4,568 & 95.4 \\
\hline 17. Liberia & December 2006 - April 2007 & 6,824 & 7,092 & 6,009 & 92.5 \\
\hline 18. Mali & November 2012 - February 2013 & 10,105 & 10,424 & 4,399 & 96.4 \\
\hline 19. Niger & February 2012 - June 2012 & 10,750 & 11,160 & 3,928 & 93.5 \\
\hline 20. Nigeria & February 2013 - June 2013 & 38,522 & 38,948 & 17,359 & 94.9 \\
\hline 21. Senegal & October 2010 - April 2011 & 7,902 & 15,688 & 4,929 & 91.2 \\
\hline 22. Sierra Leone & June 2013 - October 2013 & 12,629 & 16,658 & 7,262 & 91.8 \\
\hline \multicolumn{6}{|l|}{ CENTRAL AFRICA } \\
\hline 23. Cameroon & January 2011 - August 2011 & 14,214 & 15,426 & 7,191 & 96.4 \\
\hline 24. Congo (Brazzaville) & September 2011 - February 2012 & 11,632 & 10,819 & 5,145 & 97.4 \\
\hline 25. Congo (Democratic) & August 2013 - February 2014 & 18,171 & 18,827 & 8,656 & 98.0 \\
\hline 26. Gabon & January 2012 - May 2012 & 9,755 & 8,422 & 5,654 & 97.5 \\
\hline 27. Sao Tome \& Principe & September 2008 - January 2009 & 3,536 & 2,615 & 2,296 & 84.5 \\
\hline \multicolumn{6}{|l|}{ SOUTHERN AFRICA } \\
\hline 28. Lesotho & October 2009 - January 2010 & 9,391 & 7,624 & 3,317 & 95.6 \\
\hline 29. Namibia & May 2013 - September 2013 & 9,200 & 9,804 & 3,915 & 92.6 \\
\hline 30. Swaziland & July 2006 - February 2007 & 4,843 & 4,987 & 4,156 & 89.6 \\
\hline
\end{tabular}

and 'urban'), current occupation ('unemployed', 'professional', 'agriculture', and 'unskilled/manual work'), educational level ('no education', 'primary', 'secondary', and 'higher') and household wealth index. Wealth index is a reliable proxy indicator for economic status and it is calculated based on a standard set of household assets, dwelling characteristics, and ownership of consumer items as observed by the interviewer [29]. Each household is classified into quintiles where first quintile is the poorest $20 \%$ of the households and fifth quintile is the wealthiest $20 \%$ of the households [30].

\section{Ethics statement}

Institutional review boards of ORC Macro International Inc. and in-country institutions which implemented the survey in each country provided ethical clearance for DHSs. The interviewers explained the survey details, voluntary participation, and confidentiality of information collected to 
each participant. Informed consent was obtained from each participant. No identifiable personal information was collected during the survey and data was archived by the DHS program.

\section{Data analysis}

Prevalence rates of smoking and SLT use were estimated for each country, separately for men and women. For each country, overall weighted prevalence rates were calculated by including sample weights to account for complex sampling design adopted in DHSs. We pooled data from all 30 countries for men and women separately and calculated the weighted prevalence rates of smoking and SLT use by social factors; age groups, religion, place of residence, marital status, current occupation, education, and wealth quintiles. All weighted prevalence estimates were calculated using the 'svy' command in Stata intercool 10.0. To assess the social determinants of smoking and SLT use among men and women, logistic regression analyses were performed using country of domicile as dummy-variable controls and including within-country sample weight for each country into the regression models. For logistic regression analyses, we used the 'complex samples analysis' option in SPSS (Statistical Package for Social Sciences) to account for stratified, two-stage cluster sampling design used in DHSs.

\section{Results}

\section{Sample characteristics}

DHSs primarily aim to assess the indicators of maternal and child healthcare, resulting in larger women's sample sizes in all included SSA countries (Table 1). Overall response rates were above $90 \%$ in most countries. In Western Africa, men were not asked about SLT use in Burkina Faso (Table 2). Information regarding religion was not collected in Tanzania and Niger. From the pooled data, more than half of the male and female respondents were aged under 30 years. More than half of the men and two-thirds of the women had not received any education or were educated up to primary level only. Both male and female respondents were almost evenly distributed across the wealth quintiles. About a quarter of both men and women were Muslims and about $60 \%$ of men were affiliated to Catholic, Protestant, or other Christian denominations. Overall, the highest proportion of respondents was married but $40.6 \%$ of men and $25.9 \%$ of women were 'never in union'. Male respondents were mostly involved in agriculture (42.2\%), whereas females were mostly unemployed (35.2\%; Table 3).

\section{Prevalence of smoking and SLT use among men}

In most East African countries, prevalence rates of smoking among men were similar, ranging from $12.91 \%$ (in Rwanda) to $24.10 \%$ (in Zambia), whereas Madagascar had the highest (28.54\%) while Ethiopia had the lowest (6.75\%) prevalence of smoking. In most East African countries, prevalence of SLT use among men was very low, ranging from $0.03 \%$ (in Burundi) to $7.72 \%$ (in Comoros) except for Madagascar, where prevalence was the highest (24.66\%), followed by Mozambique (10.94\%). In Western Africa, the prevalence rate of smoking among men was high in Sierra Leone $(37.68 \%)$ and Cote d'Ivoire (24.48\%) but low in Nigeria (9.20\%) and Ghana (7.55\%). In most West African countries the prevalence of SLT use among men was low, ranging from $0.61 \%$ in Cote d'Ivore to $6.63 \%$ in Senegal. In Central Africa, the prevalence of smoking among men was the highest in Gabon (22.38\%) followed by the Democratic Republic of Congo (20.68\%), whereas prevalence of SLT use was highest in the Democratic Republic of Congo (8.67\%) followed by Congo (Brazzaville; 8.30\%). In Southern Africa, Lesotho had the highest prevalence for smoking (34.14\%), whereas the prevalence of SLT use among men was very low in most countries (1.40\% to $2.81 \%$; Table 2$)$. Men who were using tobacco mostly smoked cigarettes in all SSA countries. However, men also consumed chewing tobacco (in Niger, Mozambique, Madagascar, Ghana, Ethiopia, and Burkina Faso) and snuff (in Uganda, Senegal, Sao Tome \& Principe, Rwanda, Nigeria, Congo Brazzaville, and Benin; Figure 1).

\section{Prevalence of smoking and SLT use among women}

In most East African countries, the prevalence of smoking and SLT use among women were very low (ranging from $0.16 \%$ to $2.76 \%$ for smoking and $0.20 \%$ to $2.99 \%$ for SLT use) except in Burundi (9.89\%) for smoking and in Madagascar (19.63\%) for SLT use. Similarly, in West Africa, the prevalence of smoking and SLT use were very low (ranging from $0.02 \%$ to $0.93 \%$ for smoking and $0.23 \%$ to $3.86 \%$ for SLT use) in most countries except in Sierra Leone (6.06\% and $4.74 \%$, respectively). In Central Africa, the highest prevalence of smoking among women was in Gabon (3.11\%) and prevalence of SLT use was very low in most countries $(0.34 \%$ to 3.22\%). In Southern Africa, Lesotho had the highest prevalence of SLT use among women $(9.12 \%)$ while Namibia had the highest prevalence for smoking among women (5.87\%; Table 2). Women tobacco users in SSA countries mainly smoked cigarettes in Gabon, Swaziland, Sierra Leone, Namibia, and Sao Tome \& Principe. However, in the remaining countries, a higher proportion of women tobacco users chewed tobacco in Niger, Madagascar, Burkina Faso, Congo, Cote d'Ivore, Benin, Rwanda, Kenya, and Senegal, while the proportion of those using snuff was higher in Lesotho, Zimbabwe, Uganda, Tanzania, Zambia, Nigeria, Liberia, Congo (Brazzaville), Swaziland, and Cameroon (Figure 2). 
Table 2 Weighted prevalence estimates (95\% confidence intervals) of smoking (cigarettes, pipe, and others) and smokeless tobacco use (chewing tobacco, snuff) among men and women of $\mathbf{3 0}$ countries in sub-Saharan Africa

\begin{tabular}{|c|c|c|c|c|}
\hline \multirow[b]{2}{*}{ Country (survey year) } & \multicolumn{2}{|l|}{ MEN } & \multicolumn{2}{|l|}{ WOMEN } \\
\hline & Smoking & SLT use & Smoking & SLT use \\
\hline \multicolumn{5}{|l|}{ EASTERN AFRICA } \\
\hline Burundi (2011) & $21.24(19.75,22.73)$ & $0.03(-0.03,0.08)$ & $9.89(9.02,10.75)$ & $0.31(0.18,0.44)$ \\
\hline Comoros (2012) & $18.83(16.67,20.99)$ & $7.72(5.91,9.55)$ & $1.72(1.22,2.21)$ & $2.99(2.15,3.85)$ \\
\hline Ethiopia (2011) & $6.75(5.89,7.61)$ & $1.94(1.47,2.41)$ & $0.57(0.37,0.77)$ & $0.20(0.09,0.30)$ \\
\hline Kenya (2008) & $18.65(16.42,20.88)$ & $2.05(1.28,2.83)$ & $0.35(0.21,0.48)$ & $1.29(0.61,1.97)$ \\
\hline Madagascar (2009) & $28.54(27.15,29.94)$ & $24.66(23.00,26.32)$ & $1.56(1.18,1.95)$ & $19.63(17.86,21.40)$ \\
\hline Malawi (2010) & $17.73(16.49,18.98)$ & $0.47(0.27,0.68)$ & $0.38(0.27,0.49)$ & $0.80(0.62,0.97)$ \\
\hline Mozambique (2011) & $20.73(19.02,22.43)$ & $10.94(9.62,12.25)$ & $2.76(2.29,3.23)$ & $0.82(0.59,1.05)$ \\
\hline Rwanda (2011) & $12.91(11.96,13.86)$ & $5.80(5.14,6.47)$ & $1.01(0.83,1.19)$ & $2.73(2.39,3.07)$ \\
\hline Tanzania (2010) & $19.60(17.57,21.62)$ & $2.03(1.27,2.80)$ & $0.54(0.35,0.73)$ & $0.83(0.56,1.10)$ \\
\hline Uganda (2011) & $14.24(12.42,16.05)$ & $2.94(1.93,3.96)$ & $1.21(0.89,1.52)$ & $1.50(0.89,2.11)$ \\
\hline Zambia (2007) & $24.10(22.51,25.68)$ & $0.30(0.16,0.43)$ & $0.81(0.57,1.05)$ & $1.21(0.83,1.58)$ \\
\hline Zimbabwe (2011) & $21.99(20.63,23.35)$ & $1.59(1.20,1.99)$ & $0.16(0.09,0.24)$ & $0.38(0.23,0.52)$ \\
\hline \multicolumn{5}{|l|}{ WESTERN AFRICA } \\
\hline Benin (2012) & $8.47(7.55,9.38)$ & $4.92(4.17,5.68)$ & $0.28(0.19,0.36)$ & $0.66(0.52,0.81)$ \\
\hline Burkina Faso $(2011)^{*}$ & $21.24(19.97,22.51)$ & - & $0.09(0.04,0.14)$ & $3.86(3.22,4.48)$ \\
\hline Cote d'Ivoire (2012) & $24.48(22.67,26.29)$ & $0.61(0.34,0.89)$ & $0.39(0.19,0.60)$ & $1.27(0.97,1.58)$ \\
\hline Ghana (2008) & $7.55(6.69,8.40)$ & $1.33(0.95,1.72)$ & $0.17(0.05,0.29)$ & $0.20(0.08,0.32)$ \\
\hline Liberia (2007) & $15.48(13.86,17.10)$ & $2.34(1.49,3.19)$ & $0.93(0.63,1.24)$ & $2.37(1.68,3.06)$ \\
\hline Mali $(2012)^{*}$ & $15.86(14.63,17.09)$ & $5.06(3.96,6.16)$ & $0.19(0.01,0.28)$ & $1.03(0.69,1.38)$ \\
\hline Niger (2012) & $14.02(12.49,15.55)$ & $4.55(3.60,5.49)$ & $0.02(0.01,0.06)$ & $2.30(1.59,3.01)$ \\
\hline Nigeria (2013) & $9.20(8.56,9.84)$ & $3.78(3.33,4.23)$ & $0.22(0.15,0.29)$ & $0.46(0.31,0.60)$ \\
\hline Senegal (2011) & $14.85(13.43,16.26)$ & $6.63(5.20,8.06)$ & $0.19(0.09,0.30)$ & $0.23(0.12,0.34)$ \\
\hline Sierra Leone (2013) & $37.68(35.16,40.20)$ & $1.54(0.99,2.09)$ & $6.06(5.37,6.74)$ & $4.74(3.97,5.51)$ \\
\hline \multicolumn{5}{|l|}{ CENTRAL AFRICA } \\
\hline Cameroon (2011) & $14.77(13.71,15.82)$ & $1.94(1.52,2.36)$ & $0.57(0.41,0.74)$ & $0.94(0.59,1.28)$ \\
\hline Congo (Brazzaville) (2012) & $19.91(18.02,21.81)$ & $8.30(6.97,9.63)$ & $0.54(0.35,0.72)$ & $1.54(1.22,1.86)$ \\
\hline Congo (Republic) (2013) & $20.68(18.81,22.55)$ & $8.67(7.19,10.16)$ & $0.99(0.78,1.22)$ & $3.22(2.88,3.56)$ \\
\hline Gabon (2012) & $22.38(20.11,24.66)$ & $0.48(0.21,0.75)$ & $3.11(2.49,3.73)$ & $0.34(0.18,0.51)$ \\
\hline Sao Tome \& Principe (2009) & $5.39(4.23,6.55)$ & $2.59(1.57,3.62)$ & $0.77(0.38,1.16)$ & $0.73(0.34,1.19)$ \\
\hline \multicolumn{5}{|l|}{ SOUTHERN AFRICA } \\
\hline Lesotho (2010) & $34.14(32.13,36.14)$ & $1.40(0.94,1.86)$ & $0.34(0.19,0.49)$ & $9.12(8.37,9.87)$ \\
\hline Namibia (2007) & $21.84(20.03,23.65)$ & $1.83(1.25,2.40)$ & $5.87(5.04,6.69)$ & $2.31(1.96,2.65)$ \\
\hline Swaziland (2007) & $14.40(13.00,15.79)$ & $2.81(2.25,3.37)$ & $1.13(0.78,1.48)$ & $1.03(0.70,1.35)$ \\
\hline
\end{tabular}

*Data about SLT use was not collected from men.

Distribution of smoking and SLT use by social factors among men and women

Prevalence of smoking among rural men was higher (17.99\% vs. $15.79 \%$ ) and so was SLT use (5.73\% vs. $2.34 \%$; Table 3). Prevalence of both smoking and SLT use was higher among older men (aged $\geq 50$ years) compared to the youngest (15-19 years). For example, prevalence of smoking was $4.08 \%$ among men aged 15-19 years while it was $23.81 \%$ among men aged $40-49$ years and 20.96\% among men aged 50 years or more. Similarly, among men, the prevalence of both smoking and SLT use was highest among poorest vs. the richest $(21.96 \%$ vs. $13.41 \%$ for smoking; $7.76 \%$ vs. $1.79 \%$ for SLT use) and uneducated vs. highly education (19.88\% vs. $10.38 \%$ for smoking; $7.13 \%$ vs. $1.37 \%$ for SLT use). There was a clear gradient across ordered variables wealth and education (Table 3). The 
Table 3 Distribution of study sample and weighted prevalence estimates of smoking and smokeless tobacco use according to social factors from a pooled data set of $\mathbf{3 0}$ countries in sub-Saharan Africa

\begin{tabular}{|c|c|c|c|c|c|c|}
\hline \multirow[b]{3}{*}{ Overall prevalence } & \multicolumn{3}{|c|}{ Men $(n=169,500)$} & \multicolumn{3}{|c|}{ Women $(n=354,927)$} \\
\hline & Number (\%) & Smoking $(95 \% \mathrm{Cl})$ & SLT use $(95 \% \mathrm{Cl})$ & Number (\%) & Smoking $(95 \% \mathrm{Cl})$ & SLT use $(95 \% \mathrm{Cl})$ \\
\hline & & $17.17(16.84,17.51)$ & $4.47(4.25,4.69)$ & & $1.27(1.19,1.35)$ & $1.84(1.74,1.94)$ \\
\hline \multicolumn{7}{|l|}{ Age group } \\
\hline $15-19$ & $35,780(21.1)$ & $4.08(3.78,4.38)$ & $1.06(0.91,1.22)$ & $75,541(21.3)$ & $0.43(0.34,0.51)$ & $0.41(0.34,0.48)$ \\
\hline $20-29$ & $51,389(30.3)$ & $17.05(16.54,17.57)$ & $2.94(2.71,3.18)$ & 130,014 (36.6) & $0.90(0.81,0.99)$ & $1.04(0.95,1.13)$ \\
\hline $30-39$ & $39,705(23.4)$ & $23.09(22.48,23.69)$ & $5.24(4.88,5.60)$ & $91,373(25.7)$ & $1.58(1.45,1.71)$ & $2.34(2.18,2.50)$ \\
\hline $40-49$ & $27,541(16.2)$ & $23.81(23.07,24.56)$ & $7.58(7.11,8.06)$ & $57,999(16.3)$ & $2.75(2.53,2.96)$ & $4.78(4.49,5.06)$ \\
\hline$>50^{\natural}$ & $15,085(8.9)$ & $20.96(20.10,21.82)$ & $10.31(9.60,11.02)$ & - & - & - \\
\hline \multicolumn{7}{|l|}{ Education } \\
\hline No education & $35,592(21.0)$ & $19.88(19.14,20.62)$ & $7.13(6.67,7.60)$ & $117,279(33.0)$ & $1.88(1.73,2.03)$ & $2.59(2.40,2.79)$ \\
\hline Primary & $59,935(35.4)$ & $19.27(18.75,19.79)$ & $5.59(5.22,5.97)$ & $124,961(35.2)$ & $1.03(0.93,1.12)$ & $2.33(2.17,2.49)$ \\
\hline Secondary & 62,493 (36.9) & $15.17(14.71,15.62)$ & $2.69(2.46,2.92)$ & $100,171(28.2)$ & $0.94(0.81,1.06)$ & $0.71(0.63,0.79)$ \\
\hline Higher & $11,454(6.8)$ & $10.38(9.66,11.11)$ & $1.37(1.07,1.67)$ & $12,466(3.5)$ & $1.08(0.81,1.35)$ & $0.13(0.07,0.20)$ \\
\hline \multicolumn{7}{|l|}{ Wealth index } \\
\hline Poorest & $32,788(19.3)$ & $21.96(21.22,22.70)$ & $7.76(7.25,8.27)$ & $70,998(20.0)$ & $1.68(1.51,1.84)$ & $3.52(3.26,3.78)$ \\
\hline Poorer & $31,136(18.4)$ & $19.09(18.42,19.76)$ & $5.85(5.41,6.29)$ & 66,794 (18.8) & $1.40(1.24,1.56)$ & $2.44(2.25,2.63)$ \\
\hline Middle & $31,877(18.8)$ & $17.67(17.03,18.31)$ & $5.15(4.71,5.58)$ & $66,309(18.7)$ & $1.21(1.08,1.34)$ & $1.97(1.80,2.14)$ \\
\hline Richer & $33,743(19.9)$ & $15.79(15.18,16.40)$ & $3.29(2.97,3.60)$ & 69,322 (19.5) & $1.08(0.96,1.20)$ & $1.28(1.13,1.43)$ \\
\hline Richest & $39,956(23.6)$ & $13.41(12.85,13.97)$ & $1.79(1.54,2.04)$ & $81,504(23.0)$ & $1.09(0.95,1.23)$ & $0.53(0.44,0.62)$ \\
\hline \multicolumn{7}{|l|}{ Religion $^{\ddagger}$} \\
\hline Islam & 40,417 (23.8) & $16.41(15.75,17.07)$ & $3.91(3.54,4.27)$ & $88,552(24.9)$ & $0.97(0.85,1.08)$ & $1.04(0.90,1.19)$ \\
\hline Catholic & $35,561(21.0)$ & $20.73(20.07,21.39)$ & $5.83(5.38,6.29)$ & 73,922 (20.8) & $2.53(2.28,2.77)$ & $2.60(2.39,2.81)$ \\
\hline Protestant & $27,573(16.3)$ & $16.62(15.89,17.36)$ & $4.64(4.13,5.15)$ & $59,540(16.8)$ & $1.57(1.37,1.77)$ & $2.20(1.98,2.42)$ \\
\hline Other Christian ${ }^{\dagger}$ & $42,933(25.3)$ & $11.40(10.90,11.90)$ & $2.24(2.02,2.46)$ & $88,845(25.0)$ & $0.59(0.52,0.66)$ & $1.21(1.10,1.33)$ \\
\hline No religion* & $16,374(9.7)$ & $29.46(28.39,30.52)$ & $9.44(8.68,10.20)$ & $22,189(6.3)$ & $1.86(1.59,2.14)$ & $4.36(3.89,4.83)$ \\
\hline \multicolumn{7}{|l|}{ Marital status } \\
\hline Not in union & 68,898 (40.6) & $9.75(9.40,10.10)$ & $1.58(1.43,1.73)$ & $91,974(25.9)$ & $0.66(0.57,0.76)$ & $0.45(0.38,0.51)$ \\
\hline Married & $76,839(45.3)$ & $20.96(20.45,21.47)$ & $6.44(6.09,6.78)$ & 189,266 (53.3) & $1.12(1.03,1.21)$ & $2.20(2.06,2.33)$ \\
\hline Living together & $16,722(9.9)$ & $23.16(22.25,24.08)$ & $6.11(5.51,6.71)$ & 42,064 (11.9) & $2.35(2.12,2.59)$ & $2.03(1.82,2.24)$ \\
\hline Single ${ }^{¥}$ & $7,041(4.2)$ & $35.22(33.69,36.75)$ & $7.87(7.01,8.74)$ & $31,623(8.9)$ & $2.54(2.28,2.80)$ & $3.62(3.33,3.92)$ \\
\hline \multicolumn{7}{|l|}{ Residence } \\
\hline Urban & $59,640(35.2)$ & $15.79(15.27,16.31)$ & $2.34(2.11,2.57)$ & $121,955(34.4)$ & $1.23(1.11,1.36)$ & $0.73(0.64,0.81)$ \\
\hline Rural & $109,860(64.8)$ & $17.99(17.55,18.42)$ & $5.73(5.41,6.04)$ & $232,972(65.6)$ & $1.29(1.19,1.39)$ & $2.47(2.32,2.61)$ \\
\hline \multicolumn{7}{|l|}{ Occupation } \\
\hline Unemployed & $26,407(15.6)$ & $6.83(6.39,7.27)$ & $1.04(0.89,1.19)$ & $125,072(35.2)$ & $0.84(0.75,0.92)$ & $0.86(0.76,0.95)$ \\
\hline Professional $^{\times}$ & $26,906(15.9)$ & $14.56(13.92,15.21)$ & $2.37(2.11,2.63)$ & $72,130(20.3)$ & $1.19(1.05,1.33)$ & $0.88(0.77,0.99)$ \\
\hline Agriculture & $71,494(42.2)$ & $19.96(19.39,20.52)$ & $7.39(6.96,7.82)$ & $104,653(29.5)$ & $2.12(1.92,2.31)$ & $3.70(3.46,3.95)$ \\
\hline Unskilled & 44,693 (26.4) & $20.69(20.11,21.26)$ & $3.52(3.24,3.80)$ & $53,072(15.0)$ & $0.94(0.81,1.07)$ & $2.10(1.90,2.30)$ \\
\hline \multicolumn{7}{|c|}{$\begin{array}{l}\text { Totals do not add up to total sample of men and women for some cate } \\
\text { due to missing values. } \\
\text { "In most countries except Tanzania, Swaziland, Namibia, and Liberia me } \\
\text { "Includes various Christian faiths such as Adventist, Pentecostal, Eglise, } 2 \\
\text { *Includes traditional religions such as Vodoun in Benin, Animism, etc. } \\
{ }^{+} \text {Information about religion was not collected in Tanzania and Niger. }\end{array}$} \\
\hline
\end{tabular}




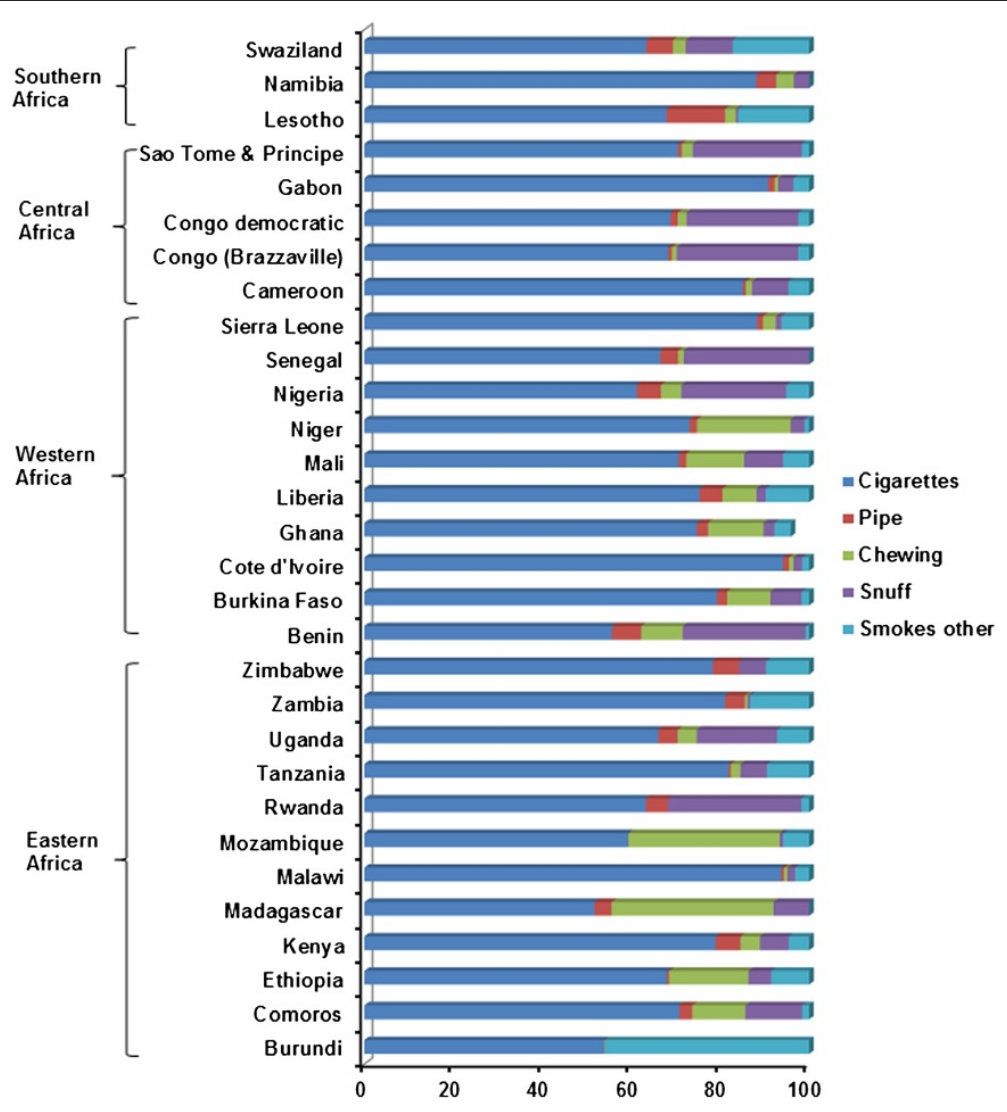

Figure 1 Proportional distribution of various tobacco products consumed among tobacco-using men in 30 sub-Saharan African countries. Percentage of respondents using multiple tobacco products was small and is not presented here.

prevalence of both smoking and SLT use was highest among single men (35.22\% and $7.87 \%$, respectively) while smoking prevalence was highest in agriculturists and unskilled/manual workers (19.96\% and $20.69 \%$, respectively) and SLT use was highest among agriculturists (7.39\%). The prevalence of both smoking and SLT use was highest (29.46\% and $9.44 \%$, respectively) among men affiliated to other/traditional religions.

The prevalence of SLT use was much higher among rural compared to urban women $(2.47 \%$ vs. $0.73 \%)$, although smoking prevalence was nearly equal $(1.29 \%$ and 1.23\%). The prevalence of both smoking and SLT use increased with age; the highest prevalence was among women aged $40-49$ years $(2.75 \%$ for smoking and $4.78 \%$ for SLT use). Similar to men, there was a gradient across the wealth and educational groups for smoking and SLT use among women (Table 3). The prevalence of both smoking and SLT use was highest among single women (2.54\% and $3.62 \%$, respectively) and among agriculturists $(2.12 \%$ and $3.70 \%$, respectively). Smoking prevalence was slightly higher (2.53\%) among Catholic women, while SLT use was highest $(4.36 \%)$ among women affiliated to other/traditional religions (Table 3).

\section{Association of smoking and SLT use with social factors among men and women}

The association of smoking and SLT use with social determinants was assessed by multivariate analyses on separate pooled datasets for men and women from 30 countries. Smoking and SLT use were associated with age for both men and women. When compared to respondents aged 15-19 years, the odds of being a smoker and SLT user were 5- to 8-fold greater for those aged 40-49 years ( $>50$ years for men; Table 4 ). Smoking among both men and women was weakly associated with education, whereas SLT use was strongly associated with education. Compared to men with a higher education, the odds of being a smoker and SLT user were 1.8- and 2.62-fold greater, respectively, for men who were uneducated. Similarly, compared to women with a higher education, the odds of being a smoker and SLT user were 2- and 11-fold greater, respectively, for women who were uneducated. Smoking among both men and women was weakly associated with wealth, whereas SLT use was strongly associated with wealth. Compared to the richest men, the odds of being a smoker and SLT user were 1.5- and 2.89-fold greater, respectively, for the poorest men. Compared to the richest women, the odds 


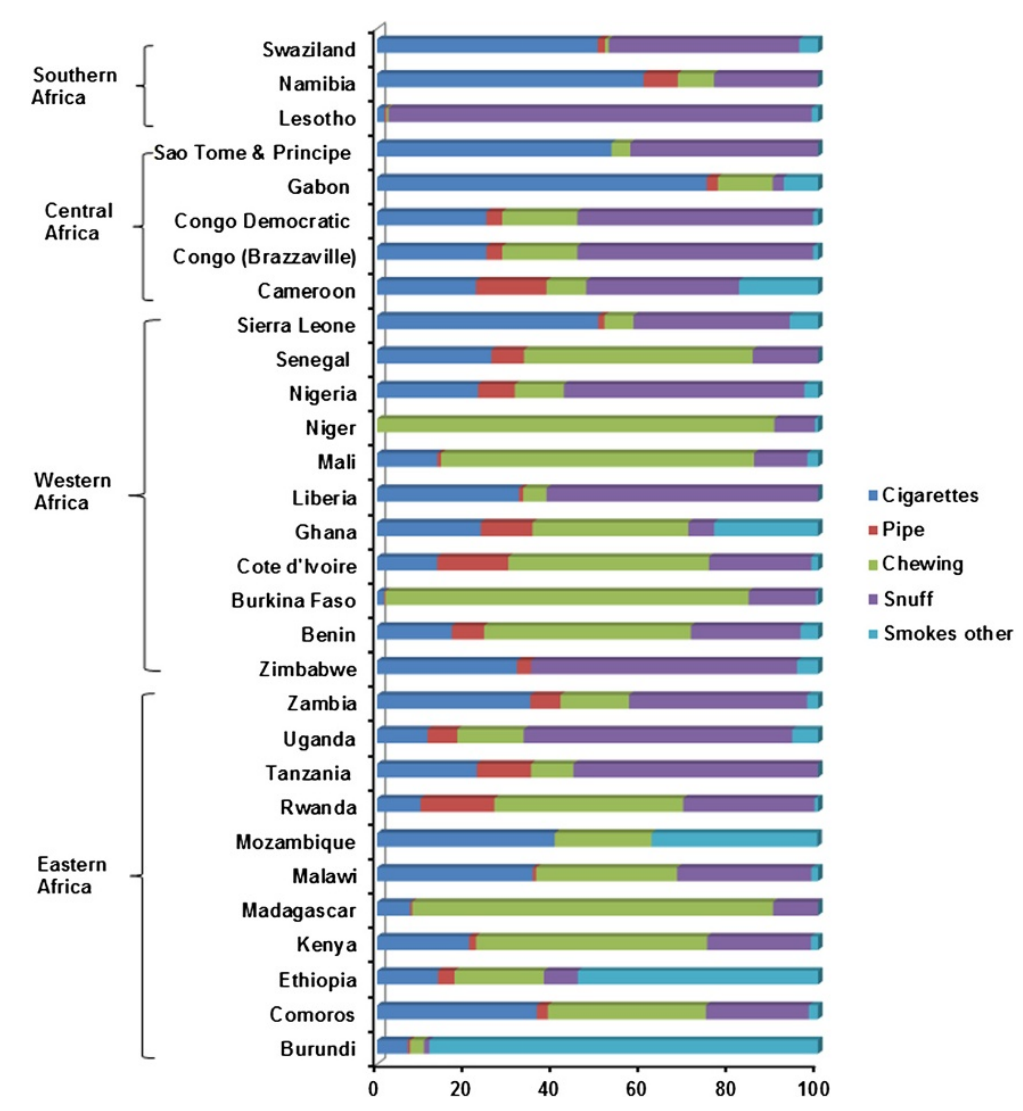

Figure 2 Proportional distributions of various tobacco products consumed among tobacco-using women in 30 sub-Saharan African countries. Percentage of respondents using multiple tobacco products was small and is not presented here.

of being a smoker and SLT user were 1.24- and 3.36-fold greater, respectively, for the poorest women. Marital status was associated with smoking and SLT use among men. Compared to men and women who were not in union, the odds of being a smoker and SLT user were about 2-fold greater (adjusted odds ratios (aORs) varied from 1.48 to 2.07 ) for men and women who were single (separated, divorced, and widowed). Among both men and women, area of residence (urban/rural) was weakly associated with smoking but unassociated with SLT use (Table 4). Men's occupation was associated (weakly) with smoking and SLT use but women's occupation was associated with SLT use only. Compared to unemployed men, the odds of being a smoker and SLT user were nearly 2-fold greater for men doing unskilled or manual work. Religious affiliation was associated with smoking and SLT use among both men and women. The odds of being a smoker and SLT user were about 2-fold greater (aORs 1.56 to 2.48) for men who followed other/traditional religions whereas the odds of being a smoker were 2-fold greater (aOR 2.37) for women who followed other/traditional religions (Table 4 ).

\section{Discussion}

Our analyses of DHS data provided national-level estimates for tobacco use in 30 out of 47 SSA countries by sex and type of tobacco consumed. The data obtained highlights the scale of the tobacco epidemic and describes the pattern of smoking and SLT use according to social groups. Among men, the prevalence of smoking (mainly cigarettes) was very high relative to SLT use in all countries except Madagascar and Mozambique. Among all the SSA countries, smoking prevalence among men was high in Sierra Leone, Lesotho, and Madagascar, where nearly a third of adult men were current smokers. In most countries, the prevalence of both smoking and SLT use among women was very low compared to men and the highest prevalence of smoking and SLT use was found in Burundi and Madagascar, respectively. Compared to men, women were using more diverse tobacco products such as cigarettes, pipe, snuff, chewing tobacco, and other types.

Since most SAA countries are poor and have lower literacy rates, it is commonly thought that the prevalence of tobacco use is lower, resulting in a low priority for tobacco control. However, following the economic 
Table 4 Social determinants (from pooled data) of smoking and smokeless tobacco use among men and women of 30 countries in sub-Saharan Africa

\begin{tabular}{|c|c|c|c|c|c|c|c|c|}
\hline & Men & & & & Women & & & \\
\hline & Smoking & $P$ value & SLT use & $P$ value & Smoking & $P$ value & SLT use & $P$ value \\
\hline & aOR (95\% Cl) & & aOR (95\% Cl) & & aOR $(95 \% \mathrm{Cl})$ & & aOR (95\% Cl) & \\
\hline Age group & & $<0.001$ & & $<0.001$ & & $<0.001$ & & $<0.001$ \\
\hline 15-19 & 1 & & 1 & & 1 & & 1 & \\
\hline $20-29$ & $0.87(0.81,0.93)$ & & $1.22(1.10,1.34)$ & & $1.62(1.47,1.80)$ & & $1.98(1.82,2.15)$ & \\
\hline $30-39$ & $0.91(0.85,0.97)$ & & $1.77(1.60,1.96)$ & & $2.58(2.28,2.91)$ & & $4.08(3.70,4.49)$ & \\
\hline $40-49$ & $1.22(1.14,1.32)$ & & $2.93(2.61,3.29)$ & & $4.30(3.36,5.51)$ & & $8.37(6.70,10.44)$ & \\
\hline$\geq 50^{\natural}$ & $5.31(4.75,5.93)$ & & $7.03(5.76,8.59)$ & & - & & - & \\
\hline Education & & $<0.001$ & & $<0.001$ & & $<0.001$ & & $<0.001$ \\
\hline Higher & 1 & & 1 & & 1 & & 1 & \\
\hline Secondary & $0.90(0.85,0.95)$ & & $1.15(1.05,1.26)$ & & $1.80(1.59,2.04)$ & & $1.49(1.36,1.64)$ & \\
\hline Primary & $1.13(1.06,1.21)$ & & $1.75(1.56,1.96)$ & & $1.88(1.60,2.22)$ & & $2.97(2.56,3.46)$ & \\
\hline No education & $1.80(1.61,2.00)$ & & $2.62(2.04,3.36)$ & & $2.00(1.47,2.72)$ & & $10.68(6.60,17.26)$ & \\
\hline Wealth index & & $<0.001$ & & $<0.001$ & & $<0.001$ & & $<0.001$ \\
\hline Richest & 1 & & 1 & & 1 & & 1 & \\
\hline Richer & $1.16(1.10,1.23)$ & & $1.30(1.18,1.43)$ & & $1.13(1.00,1.28)$ & & $1.33(1.21,1.47)$ & \\
\hline Middle & $1.23(1.16,1.31)$ & & $1.32(1.18,1.47)$ & & $1.27(1.10,1.46)$ & & $1.49(1.34,1.66)$ & \\
\hline Poorer & $1.38(1.29,1.48)$ & & $1.92(1.68,2.18)$ & & $1.37(1.18,1.58)$ & & $2.05(1.79,2.34)$ & \\
\hline Poorest & $1.51(1.39,1.64)$ & & $2.89(2.40,3.50)$ & & $1.24(1.02,1.50)$ & & $3.36(2.71,4.16)$ & \\
\hline Religion & & $<0.001$ & & $<0.001$ & & $<0.001$ & & $<0.001$ \\
\hline Islam & 1 & & 1 & & 1 & & 1 & \\
\hline Catholic & $1.67(1.53,1.83)$ & & $1.62(1.33,1.99)$ & & $1.95(1.49,2.54)$ & & $1.52(1.18,1.96)$ & \\
\hline Protestant & $1.40(1.30,1.50)$ & & $0.88(0.77,0.99)$ & & $1.04(0.87,1.25)$ & & $0.77(0.67,0.90)$ & \\
\hline Other Christian $^{\dagger}$ & $2.08(1.92,2.26)$ & & $1.11(0.96,1.28)$ & & $2.10(1.70,2.59)$ & & $0.99(0.84,1.16)$ & \\
\hline No Religion* & $2.48(2.30,2.67)$ & & $1.56(1.34,1.82)$ & & $2.37(1.91,2.94)$ & & $1.13(0.95,1.35)$ & \\
\hline Marital status & & $<0.001$ & & $<0.001$ & & $<0.001$ & & $<0.001$ \\
\hline Not in Union & 1 & & 1 & & 1 & & 1 & \\
\hline Married & $1.66(1.52,1.82)$ & & $1.21(1.02,1.44)$ & & $1.11(0.96,1.28)$ & & $1.01(0.88,1.16)$ & \\
\hline Living Together & $1.93(1.78,2.09)$ & & $1.29(1.12,1.49)$ & & $1.58(1.39,1.80)$ & & $1.25(1.13,1.38)$ & \\
\hline Single ${ }^{¥}$ & $2.07(1.89,2.26)$ & & $1.48(1.26,1.75)$ & & $2.04(1.68,2.49)$ & & $1.79(1.48,2.16)$ & \\
\hline Residence & & $<0.001$ & & 0.878 & & $<0.001$ & & 0.288 \\
\hline Urban & 1 & & 1 & & 1 & & 1 & \\
\hline Rural & $1.12(1.06,1.19)$ & & $1.01(0.90,1.14)$ & & $1.52(1.31,1.76)$ & & $0.92(0.79,1.07)$ & \\
\hline Occupation & & $<0.001$ & & $<0.001$ & & 0.051 & & $<0.001$ \\
\hline Unemployed & 1 & & 1 & & 1 & & 1 & \\
\hline Professional $^{\times}$ & $1.13(1.07,1.19)$ & & $0.85(0.76,0.93)$ & & $0.99(0.82,1.20)$ & & $0.88(0.76,1.02)$ & \\
\hline Agriculture & $1.37(1.28,1.46)$ & & $1.29(1.13,1.49)$ & & $1.02(0.85,1.23)$ & & $1.30(1.10,1.54)$ & \\
\hline Unskilled & $1.82(1.68,1.97)$ & & $1.71(1.44,2.04)$ & & $1.18(0.99,1.40)$ & & $1.11(0.94,1.30)$ & \\
\hline
\end{tabular}

Multivariate analyses were statistically controlled for age, education, wealth index, religion, marital status, type of residence, and occupation; aOR, Adjusted odds ratios; $\mathrm{Cl}$, Confidence interval; SLT, Smokeless tobacco.

"In most countries men older than 49 years (i.e., up to 54,59 , or 64 years) were surveyed.

${ }^{\dagger}$ Includes various Christian faiths such as Adventist, Pentecostal, Eglise, Zionist, etc.

*Includes traditional religions such Vodoun in Benin, Animism etc.

${ }^{¥}$ Single includes widowed, divorced, separated, and not living together any longer.

${ }^{\times}$Professional includes technical, manager, clerical and business or sales; unskilled/manual includes household and domestic work other than agriculture. 
growth currently experienced in many SSA countries, it is estimated that smoking prevalence will increase [31]. The lower prevalence estimates for most SSA countries presented herein were comparable to those in Pampel's study from 14 SSA countries [21]. A systematic review has also concluded that adult tobacco use prevalence in many SSA countries is lower than in developed and other developing countries [22]. The very small differences in prevalence estimates between our study and those of Pampel's indicate that the prevalence has changed minimally or else the differences may have been solely due to sampling errors. Nevertheless, another DHS-based study reported that prevalence of smoking among Ghanaian men had decreased by $1.7 \%$ between 2003 and 2008 [23]. Further, the current smoking and SLT use prevalence in most of the SSA countries, except Madagascar, Sierra Leone, and Lesotho, was much lower than in South and South-East Asian countries [15]. However, the current smoking prevalence estimates presented herein cannot be compared with those in Nigeria and Uganda assessed by GATS [20] or with the WHS [17], which included 14 SSA countries, since these surveys defined current smoking as smoking any form of tobacco either daily or occasionally $[17,19]$. Moreover, our estimates are also different from those by $\mathrm{Ng}$ et al. [5], since the authors adopted a different definition of daily smoking and used comprehensive data sources and robust statistical analyses.

Overall, prevalence rates of smoking and SLT use among both men and women in 30 SSA countries were much lower than in South and South-East Asian countries [15] and other regions of the world [5,32]. A higher prevalence of SLT use among men was found in some SSA countries only, for example, chewing tobacco in Madagascar [24] and Mozambique [25], and snuff inhalation in Rwanda and Senegal. Prevalence of SLT use among women was very low in most SSA countries except in Madagascar (mainly chewing tobacco) [24] and Lesotho (mainly inhaling snuff), unlike the pattern in South Asian countries where both men and women used more diverse types of SLT products [15]. A higher prevalence of SLT use among men and women was reported in India, Pakistan, Nepal, and Bangladesh, but not in other South-East Asian countries [15]. Thus, the high prevalence of SLT use among men and women in Madagascar may be explained by a high proportion of Madagascans having South Asian descent where SLT use is very high [23]. Sierra Leone had the highest prevalence of smoking among men, consistent with a previous study [23]. However, of all SSA countries, Burundi had the highest prevalence $(9.8 \%)$ of smoking among women. The lower prevalence of smoking and SLT use among women in most SSA countries is in accordance with an earlier study [19]. A positive gradient by age among both men and women for smoking has been previously reported $[15,19,21,22]$. This pattern may be explained by cohort effects, i.e., smoking was less likely to be initiated in more recent decades, or by age effects, i.e., respondents continued to initiate as they grew older. However, we could not assess whether the positive gradient by age was caused by cohort or age effects since we analyzed single cross-sectional survey data from each country. Previous studies have reported the existence of wealth-related inequalities in smoking [17] and the social determinants of tobacco use [19] in LMICs. These studies indicated that, in most LMICs, the poorest men and women were more likely to smoke than the richest, which is similar to our results. In SSA countries, SLT use was strongly associated with wealth, i.e., poorer men and women were more likely to use SLT, similar to the findings from South and South-East Asian countries [15]. It is thought that poorer people may consume tobacco to suppress their hunger [33] since many smokers believe that smoking has an appetite-suppressing effect; many tobacco companies have exploited this by introducing appetite suppressant additives to the cigarettes [34]. Compared to men and women with a higher education, uneducated men and women were more likely to smoke and use SLT, consistent with the results of previous studies from Africa [21] and other regions [19]. Less educated (illiterate) people may be more vulnerable to tobacco use as they lack knowledge about their adverse health effects [35] or else this pattern may be due to parental influence, peer pressure [36], and cultural acceptance [37].

Cigarette smoking has been reported to be higher among urban residents [21,38]; however, in our study, rural men and women in SSA countries were more likely to smoke. Our findings suggest that perhaps smokers who are usually poor and uneducated may be living in rural areas. In our study, Catholic, traditional religions, or no religious affiliation were associated with smoking and SLT use, which may likely be a residual confounder. Although none of the religions promote smoking or other unhealthy behaviors, there is no conclusive evidence for this negative relationship between religion and tobacco use [39]. As compared to those who were never in union, single men (separated, divorced, or widowed) were more likely to use tobacco; this was also the case for married women. These findings are not consistent with our previous studies or with others from Africa $[15,21,23,40]$. Our analyses show that agriculturists and unskilled or manual workers had a higher risk of smoking or SLT use, which is in accordance to a previous study in 14 SSA countries [21] and another in the United States of America [41]. Nevertheless, we agree that occupation, which reflects an individual's social standing, is also related to an individual's education and income [42] and therefore social standing affects health and health behaviors [43]. 
In general, the prevalence of smoking and SLT use was very low among women, in agreement with previous reports from SSA countries [21,22]. However, the higher prevalence of smoking among women in Burundi, Sierra Leone, and Namibia, and SLT use in Madagascar and Lesotho warrants gender-specific tobacco control interventions in these countries. Our analysis identified that poor, uneducated or less educated (up to primary school), agriculturists, and manual or unskilled workers as the most vulnerable groups. Research has shown that in lower socio-economic groups, who already have a scarce income, smoking may divert their resources from education, health care, housing, and quality food to purchase cigarettes [44]. Even though tobacco use is generally lower in SSA countries, they have a higher burden of nutrition and communicable disease [45] and may face an additional burden from non-communicable diseases [46] if timely action is not taken to curb this early-stage tobacco epidemic. To reduce the burden of tobacco-related ill health, interventions should be directed at eliminating its root causes such as illiteracy and poverty itself [17]. There is a need for the relevant authorities to act by addressing the disparities in tobacco use, failing which inequalities in health may widen further [16]. As of July 2014, 42 of the 47 SSA countries had ratified the FCTC, whose provisions include a ban on tobacco advertising, promotions, and partnerships, warning labels on tobacco product packages, measures to prevent exposure to second hand smoke, and increased taxation [7]. It is necessary that all SSA countries ratify the FCTC, especially Malawi and Mozambique, which have a higher smoking prevalence.

Analyses of DHSs provided a regional overview of the tobacco epidemic and such data may be utilized for monitoring the tobacco epidemic at country-level and assess prevalence by population subgroups. If DHSs in more countries collect tobacco use data, an updated analysis can provide a complete scenario of tobacco use in the SSA region. In a vast continent such as Africa, prevalence of tobacco use is lower than in other regions, but varies much across the 30 countries included herein. For example, smoking among men was $5.4 \%$ in Sao Tome \& Principe but $37.7 \%$ in Sierra Leone. What can explain the between-country differences in prevalence of smoking and SLT use? Such inter-country variations may be explained by country characteristics such as the economy, i.e., gross domestic product, cultural factors, access of tobacco companies to sales, tobacco control policies, and pricing of tobacco products. Nevertheless, we did not study these factors as it was beyond the scope of this paper. Further research using country-level aggregate data about these factors and multi-level modeling may provide a better understanding about the reasons for inter-country variations in tobacco use.
Prevalence estimates retrieved from DHS data have some limitations due to the survey design and questions asked to assess tobacco use. DHSs have limited the age of men and women respondents from 15-64 and 15-49 years, respectively. Therefore, true population prevalence rates may be underestimated if the prevalence rates among older men ( $>64$ years) and women ( $>49$ years) were higher. The association between social factors and tobacco use lacks a temporal relationship due to the cross-sectional design of the DHSs. We could only estimate current smoking and current SLT use since limited information was collected about tobacco use. Tobacco use based on self-reports may have been underreported due to stigma, especially among the young and women, leading to misclassification bias and underestimation of prevalence rates. However, there was no means to verify self-reported tobacco use by estimating biomarkers such as urinary cotinine levels.

\section{Conclusions}

The prevalence of smoking among women was much lower than among men, but showed similar social patterns. Tobacco control strategies should target the poor, not (least) educated, and agricultural and unskilled workers, who are the most vulnerable social groups in the SSA region. DHSs can provide reliable estimates for surveillance of tobacco use at country-level and by social groups. As most SSA countries are at the early stages of the tobacco epidemic, tobacco control efforts in Africa should focus on health promotion to stop the initiation of tobacco use in addition to cessation.

\section{Abbreviations}

aORs: Adjusted odds ratios; DHSs: Demographic and Health Surveys; FCTC: Framework Convention on Tobacco Control; ITC: International Tobacco Control; LMICs: Low- and middle-income countries; ORC: Opinion Research Corporation; SSA: Sub-Saharan African; SLT: Smokeless tobacco; WHS: World Health Surveys.

\section{Competing interests}

The authors declare that they have no competing interests.

\section{Authors' contributions}

CTS was the principal author who conceptualized the manuscript, performed data analysis and prepared tables, wrote the first draft of background and methods, revised results and discussion. PMS assisted in conceptualization of the manuscript, wrote first draft of results and discussion and revised the final draft of the manuscript. SS assisted in conceptualization of the manuscript, assisted in data analyses and preparation of tables, revised final draft of the manuscript. All authors read and approved the final manuscript.

\section{Acknowledgements}

Authors thank the Demographic and Health Surveys (DHS) Program for providing us access to data of twenty nine countries of the Sub-Saharan Africa region. We also thank Ms. Esvini Panirchellvum, project research assistant for her help in preparing this manuscript.

\section{Author details}

'Department of Population Medicine, Faculty of Medicine and Health Sciences, Universiti Tunku Abdul Rahman, Bandar Sungai Long, Selangor 43000, Malaysia. ${ }^{2}$ Department of Community Health Sciences, Patan 
Academy of Health Sciences (PAHS), P. O. Box 26500, Lagankhel-5, Lalitpur, Kathmandu 44700, Nepal. ${ }^{3}$ Department of Preclinical Sciences, Faculty of Medicine and Health Sciences, Universiti Tunku Abdul Rahman, Bandar Sungai Long, Selangor 43000, Malaysia.

Received: 20 July 2014 Accepted: 21 November 2014 Published online: 18 December 2014

\section{References}

1. Mathers CD, Fat DM, Boerma JT: The Global Burden of Disease: 2004 Update. Geneva: World Health Organization; 2008.

2. Mathers CD, Loncar D: Projections of global mortality and burden of disease from 2002 to 2030. PLoS Med 2006, 3:e442.

3. Lim SS, Vos T, Flaxman AD, Danaei G, Shibuya K, Adair-Rohani H, Amann M, Anderson HR, Andrews KG, Aryee M, Atkinson C, Bacchus LJ, Bahalim AN, Balakrishnan K, Balmes J, Barker-Collo S, Baxter A, Bell ML, Blore JD, Blyth F, Bonner C, Borges G, Bourne R, Boussinesq M, Brauer M, Brooks P, Bruce NG, Brunekreef B, Bryan-Hancock C, Bucello C, et al: A comparative risk assessment of burden of disease and injury attributable to 67 risk factors and risk factor clusters in 21 regions, 1990-2010: a systematic analysis for the Global Burden of Disease Study 2010. Lancet 2012, 380:2224-2260.

4. Ezzati M, Lopez AD: Estimates of global mortality attributable to smoking in 2000. Lancet 2003, 362:847-852.

5. $\mathrm{Ng} \mathrm{M}$, Freeman MK, Fleming TD, Robinson M, Dwyer-Lindgren $L$, Thomson B, Wollum A, Sanman E, Wulf S, Lopez AD, Murray CJ, Gakidou E: Smoking prevalence and cigarette consumption in 187 countries, 1980-2012. JAMA 2014, 311:183-192.

6. World Health Organization: WHO Report on the Global Tobacco Epidemic, 2013: Enforcing Bans on Tobacco Advertising, Promotion and Sponsorship. Geneva: World Health Organization; 2013.

7. World Health Organization: WHO Framework Convention on Tobacco Control. Geneva: World Health Organization; 2014.

8. Warren CW, Asma S, Lee J, Lea V, Mackay J: Global tobacco surveillance system. In The GTSS Atlas. Atlanta, Georgia: Centers for Disease Control and Prevention; 2009

9. Bonita R, De C, Dwyer T, Jamrozik K, Winkelmann R: The WHO Stepwise Approach to Surveillance (STEPS) of NCD Risk Factors. Geneva: World Health Organization; 2001.

10. Ustün TB, Chatterji S, Mechbal A, Murray CJ: The world health surveys. In Health Systems Performance Assessment: Debates, Methods and Empiricism. Geneva: World Health Organization; 2003:797.

11. Fong GT, Cummings KM, Shopland DR: Building the evidence base for effective tobacco control policies: the International Tobacco Control Policy Evaluation Project (the ITC Project). Tob Control 2006, 15:iii1-iii2.

12. Sinha DN, Gupta PC, Ray CS, Singh PK: Prevalence of smokeless tobacco use among adults in WHO South-East Asia. Indian J Cancer 2012, 49:342.

13. Boffetta P, Hecht S, Gray N, Gupta P, Straif K: Smokeless tobacco and cancer. Lancet Oncol 2008, 9:667-675.

14. Gupta PC, Ray CS: Smokeless tobacco and health in India and South Asia. Respirology 2003, 8:419-431.

15. Sreeramareddy CT, Pradhan PM, Mir IA, Sin S: Smoking and smokeless tobacco use in nine South and Southeast Asian countries: prevalence estimates and social determinants from Demographic and Health Surveys. Popul Health Metr 2014, 12:22.

16. Harper S, McKinnon B: Global socioeconomic inequalities in tobacco use internationally comparable estimates from the World Health Surveys. Cancer Causes Control 2012, 23:11-25.

17. Hosseinpoor AR, Parker LA, D'Espaignet ET, Chatterji S: Socioeconomic inequality in smoking in low-income and middle-income countries: results from the World Health Survey. PLoS One 2012, 7:e42843.

18. Jarvis MJ, Wardle J: Social patterning of individual health behaviours: the case of cigarette smoking. In Social Determinants of Health. Edited by Marmot M, Wilkinson RG. Oxford: Oxford University Press; 2005.

19. Palipudi KM, Gupta PC, Sinha DN, Andes LJ, Asma S, McAfee T: Social determinants of health and tobacco use in thirteen low and middle income countries: evidence from Global Adult Tobacco Survey. PLoS One 2012, 7:e33466.

20. Centre for Disease Control: Global Tobacco Control. 2014. [http://www.cdc gov/tobacco/global/]. Accessed 11-9-2014.

21. Pampel F: Tobacco use in sub-Sahara Africa: estimates from the demographic health surveys. Soc Sci Med 2008, 66:1772-1783.
22. Townsend L, Flisher AJ, Gilreath T, King G: A systematic literature review of tobacco use among adults 15 years and older in sub-Saharan Africa. Drug Alcohol Depend 2006, 84:14-27.

23. Doku D, Darteh EKM, Kumi-Kyereme A: Socioeconomic inequalities in cigarette smoking among men: evidence from the 2003 and 2008 Ghana demographic and health surveys. Arch Public Health 2013, 71:9.

24. Mamudu HM, John RM, Veeranki SP, Ouma AE: The odd man out in Sub-Saharan Africa: understanding the tobacco use prevalence in Madagascar. BMC Public Health 2013, 13:856

25. Padrao P, Damasceno A, Silva-Matos C, Carreira H, Lunet N: Tobacco consumption in Mozambique: use of distinct types of tobacco across urban and rural settings. Nicotine Tob Res 2013, 15:199-205.

26. The DHS Program: Demographic and Health Surveys. Calverton, MD: Macro; 2014

27. Corsi DJ, Neuman M, Finlay JE, Subramanian SV: Demographic and health surveys: a profile. Int J Epidemiol 2012, 41:1602-1613.

28. The Demographic and Health Surveys Program. 2014. [http://www. dhsprogram.com/]

29. Vyas S, Kumaranayake L: Constructing socio-economic status indices: how to use principal components analysis. Health Policy Plan 2006, 21:459-468.

30. Rutstein SO, Johnson K: Demographic and Health Survey Wealth Index. MEASURE DHS. ORC Macro: Calverton, MD; 2004.

31. Blecher E, Ross H: Tobacco use in Africa: Tobacco Control through Prevention American Cancer Society; 2013. http://www.cancer.org/acs/groups/content/ @internationalaffairs/documents/document/acspc-041294.pdf.

32. Eriksen M, Mackay J, Ross H: The Tobacco Atlas. USA: American Cancer Society; 2013.

33. Boyle P: Tobacco: Science, Policy and Public Health. Oxford: Oxford University Press; 2010.

34. Gonseth S, Jacot-Sadowski I, Diethelm PA, Barras V, Cornuz J: The tobacco industry's past role in weight control related to smoking. Eur J Public Health 2012, 22:234-237.

35. Siahpush M, McNeill A, Hammond D, Fong GT: Socioeconomic and country variations in knowledge of health risks of tobacco smoking and toxic constituents of smoke: results from the 2002 International Tobacco Control (ITC) Four Country Survey. Tob Control 2006, 15:iii65-iii70.

36. Simons-Morton B, Haynie DL, Crump AD, Eitel P, Saylor KE: Peer and parent influences on smoking and drinking among early adolescents. Health Educ Behav 2001, 28:95-107.

37. David A, Esson K, Perucic AM, Fitzpatrick C: Tobacco use: equity and social determinants. In Equity, Social Determinants and Public Health Programmes. Geneva: World Health Organization; 2010:199.

38. Völzke H, Neuhauser H, Moebus S, Baumert J, Berger K, Stang A, Ellert U, Werner A, Döring A: Urban-rural disparities in smoking behaviour in Germany. BMC Public Health 2006, 6:146.

39. Garrusi B, Nakhaee N: Religion and smoking: a review of recent literature. Int J Psychiatry Med 2012, 43:279-292.

40. Sreeramareddy CT, Ramakrishnareddy N, Harsha KH, Sathian B, Arokiasamy JT: Prevalence, distribution and correlates of tobacco smoking and chewing in Nepal: a secondary data analysis of Nepal Demographic and Health Survey-2006. Subst Abuse Treat Prev Policy 2011, 6:33.

41. Barbeau EM, Krieger N, Soobader MJ: Working class matters: socioeconomic disadvantage, race/ethnicity, gender, and smoking in NHIS 2000. Am J Public Health 2004, 94:269-278.

42. Galobardes B, Shaw M, Lawlor DA, Lynch JW, Smith GD: Indicators of socioeconomic position (part 1). J Epidemiol Community Health 2006, 60:7-12.

43. Galobardes B, Shaw M, Lawlor DA, Lynch JW: Indicators of socioeconomic position (part 2). J Epidemiol Community Health 2006, 60:95.

44. Efroymson D, Ahmed S, Townsend J, Alam SM, Dey AR, Saha R, Dhar B, Sujon Al, Ahmed KU, Rahman O: Hungry for tobacco: an analysis of the economic impact of tobacco consumption on the poor in Bangladesh. Tob Control 2001, 10:212-217.

45. Lozano R, Naghavi M, Foreman K, Lim S, Shibuya K, Aboyans V, Abraham J, Adair T, Aggarwal R, Ahn SY, Alvarado M, Anderson HR, Anderson LM, Andrews KG, Atkinson C, Baddour LM, Barker-Collo S, Bartels DH, Bell ML, Benjamin EJ, Bennett D, Bhalla K, Bikbov B, Bin Abdulhak A, Birbeck G, Blyth F, Bolliger I, Boufous S, Bucello C, Burch M, et al: Global and regional mortality from 235 causes of death for 20 age groups in 1990 and 2010: a systematic analysis for the Global Burden of Disease Study 2010. Lancet 2012, 380:2095-2128. 
46. Beaglehole R, Bonita R, Horton R, Adams C, Alleyne G, Asaria P, Baugh V, Bekedam H, Billo N, Casswell S, Cecchini M, Colagiuri R, Colagiuri S, Collins T, Ebrahim S, Engelgau M, Galea G, Gaziano T, Geneau R, Haines A, Hospedales J, Jha P, Keeling A, Leeder S, Lincoln P, McKee M, Mackay J, Magnusson R, Moodie R, Mwatsama M, et al: Priority actions for the non-communicable disease crisis. Lancet 2011, 377:1438-1447.

Submit your next manuscript to BioMed Central and take full advantage of:

- Convenient online submission

- Thorough peer review

- No space constraints or color figure charges

- Immediate publication on acceptance

- Inclusion in PubMed, CAS, Scopus and Google Scholar

- Research which is freely available for redistribution 